INTER-LEGERE

ENSINO DE CIÊNCIAS SOCIAIS NO BRASIL: A FORMAÇẪO DO

PENSAMENTO SOCIAL BRASILEIRO E AS LUTAS PELA INSTITUCIONALIZAÇÃO NO ENSINO MÉDIO

Karla Danielle da Silva Souza

Fernando Francelino Lopes Júnior

\title{
ENSINO DE CIÊNCIAS SOCIAIS NO BRASIL: A FORMAÇÃO DO PENSAMENTO SOCIAL BRASILEIRO E AS LUTAS PELA INSTITUCIONALIZAÇÃO NO ENSINO MÉDIO
}

\section{EDUCATION OF SOCIAL SCIENCES IN BRAZIL: THE FORMATION OF BRAZILIAN SOCIAL THOUGHT AND THE STRUGGLES FOR INSTITUTIONALIZATION IN HIGH SCHOOL}

Karla Danielle da Silva Souza Fernando Francelino Lopes Júnior

\section{RESUMO}

O Ensino de Ciências Sociais no Brasil tem sua trajetória marcada por muitos elementos: políticos, ideológicos e culturais. Seu percurso de busca pela consolidação na Educação Básica está relacionado à formação do pensamento social brasileiro que transita entre a importação de teorias estrangeiras ao modelo nacional até as mudanças no imaginário da cultura e identidade brasileiras. As lutas em busca da institucionalização do Ensino de Ciências Sociais/Ensino de Sociologia (nomenclatura que recebe na etapa do Ensino Médio) se configuram, inicialmente, como necessidade de uma Sociologia pragmática e crítica e também como instrumento de cidadania. Posteriormente, a presença da Sociologia na Rede Básica se apresenta a partir de duas especificidades, características próprias: estranhamento e desnaturalização, conforme apontam os documentos oficiais que versam sobre essa etapa de ensino, OCN's (Orientações Curriculares Nacionais) e PCN's (Parâmetros Curriculares Nacionais). Esse trabalho se estrutura a partir da relevância de pensadores como Antônio Cândido, Silvio Romero, Manoel Bonfim, Alberto 


\section{ENSINO DE CIÊNCIAS SOCIAIS NO BRASIL: A FORMAÇÂO DO \\ PENSAMENTO SOCIAL BRASILEIRO E AS LUTAS PELA INSTITUCIONALIZAÇÃO NO ENSINO MÉDIO \\ Karla Danielle da Silva Souza \\ Fernando Francelino Lopes Júnior}

Tôrres, Euclides da Cunha, Oliveira Vianna, Florestan Fernandes, Octavio lanni, Sérgio Buarque de Holanda, Gilberto Freyre, entre outros, para a formação do pensamento social brasileiro. Procuramos estabelecer um diálogo entre as contribuições desses autores e a consolidação da obrigatoriedade do Ensino de Sociologia no Educação Básica no Brasil. Para isso, contamos com a colaboração de autores como Dimas (2009), Florêncio (2009), Kinzo (2001), Liedke Filho (2005) e outros. Nossas reflexões iniciais apontam para um cenário permeado por uma trajetória de transformações, avanços e retrocessos no contexto político e social nacional acompanhado de mudanças na formação do pensamento social brasileiro. Nesse sentido, compreendemos a importância dos estudos desenvolvidos pelos autores citados para as interpretações sobre - Brasil, sua cultura e sua identidade até as configurações atuais. Esses fatores desencadeiam processos significativos que perpassam os movimentos que vão resultar na presença do Ensino de Ciências Sociais nos currículos acadêmicos e escolares.

Palavras-chave: Pensamento. Sociologia. Ensino.

\section{ABSTRACT}

The Teaching of Social Sciences in Brazil has its trajectory marked by many elements: political, ideological and cultural. It's course of research for consolidation in Basic Education is related to the formation of Brazilian social thought that transits between an import of foreign theories to the national model and changes in the imaginary of Brazilian culture and identity. As struggles in search of institutionalization of the Teaching of Social Sciences / Teaching of Sociology (nomenclature that receives in the stage of High School) they are initially configured as a need for a pragmatic and critical Sociology as well as an instrument of citizenship. Subsequently, a presence of Sociology in the Basic 


\section{ENSINO DE CIÊNCIAS SOCIAIS NO BRASIL: A FORMAÇÂO DO \\ PENSAMENTO SOCIAL BRASILEIRO E AS LUTAS PELA INSTITUCIONALIZAÇÃO NO ENSINO MÉDIO \\ Karla Danielle da Silva Souza \\ Fernando Francelino Lopes Júnior}

Education Network presents itself from two specificities, its own characteristics: strangement and denaturalization, according to the official documents that refer to this stage of teaching, OCN's (National Curricular Guidelines) and PCN's (National Curricular Parameters). This work is structured by the relevance of thinkers such as Antônio Cândido, Silvio Romero, Manoel Bonfim, Alberto Tôrres, Euclides da Cunha, Oliveira Vianna, Florestan Fernandes, Octavio Ianni, Sérgio Buarque de Holanda, Gilberto Freyre, among others, of Brazilian social thought. We seek to establish a dialogue between the contributions of authors and a consolidation of the compulsory teaching of Sociology in Basic Education in Brazil. For this, we rely on a collaboration of authors such as Dimas (2009), Florêncio (2009), Kinzo (2001), Liedke Filho (2005) and others. Our initial reflections point to a circumstances permeated by a trajectory of transformations, advances and setbacks in the national political and social context accompanied by changes in the formation of Brazilian social thought. In this sense, let us understand the importance of the studies developed by the authors cited for interpretations about Brazil, its culture and its identity, as well as updates. These factors trigger significant processes that permeate the movements that are resulting in the presence of Social Science Teaching in academic and school curricula.

Keywords: Thought. Sociology. Teaching.

\section{BREVE HISTÓRICO DA SOCIOLOGIA NO BRASIL}

A Sociologia no Brasil se desenvolve a partir dos anos 1880 marcada por dois períodos, um primeiro até 1930 e um posterior a 1940. Com uma significativa transição entre os anos 1930 e 1940. Inicialmente, era praticada por intelectuais não especializados e como interesses teóricos mais gerais sobre a sociedade brasileira, conforme aponta Antônio Candido (2006). 


\section{ENSINO DE CIÊNCIAS SOCIAIS NO BRASIL: A FORMAÇÃO DO \\ PENSAMENTO SOCIAL BRASILEIRO E AS LUTAS PELA INSTITUCIONALIZAÇÃO NO ENSINO MÉDIO \\ Karla Danielle da Silva Souza \\ Fernando Francelino Lopes Júnior}

Para Candido (2006), a formação do pensamento da Sociologia no Brasil é atravessada por duas características: Direito e Evolucionismo. Seu desenvolvimento esteve ligado a concepções fundamentadas no Evolucionismo científico e filosófico por alguns juristas que tiveram um papel social dominante no Brasil no período oitocentista, como forma de interpretar as relações sociais e econômicas e organizar um projeto de Estado moderno para o país. Tratouse de um período de elaboração das leis e definição de ocupações administrativas, por isso, ficava a cargo dos juristas a função de interpretar a sociedade.

Todavia, o espírito científico que se funda na Biologia acaba por influenciar as teorias sobre a sociedade e, nesse sentido, os juristas também se contaminam por essas concepções científicas para interpretar o Brasil. Desse modo, influenciados por tais ideias, se aproximam de forma mais intensa com outros profissionais que constituíam a classe de intelectuais do país, médicos e engenheiros, principalmente, buscando um caráter científico para pensar a sociedade brasileira.

Nesse sentido, a orientação científica no Brasil vai ser inaugurada através dos juristas, contando com a colaboração de engenheiros e principalmente de médicos, como afirma Candido (2006). Nesse contexto, as orientações que marcam o desenvolvimento da Sociologia se pautam em perspectivas evolucionistas, fundamentando o pensamento sob uma ótica evidentemente biológica, além de uma atenção com as etapas históricas a partir do critério de evolução. Vale ressaltar que a noção de evolucionismo era importada às realidades específicas com a intenção de pensar o passado do país para construir um projeto de desenvolvimento para o futuro enquanto nação. Os critérios de raça evidenciam esse processo de formação de uma identidade, transitando entre elemento negativo e positivo conforme o momento histórico e os projetos de Estado e da elite intelectual. 


\section{ENSINO DE CIÊNCIAS SOCIAIS NO BRASIL: A FORMAÇÃO DO \\ PENSAMENTO SOCIAL BRASILEIRO E AS LUTAS PELA INSTITUCIONALIZAÇÃO NO ENSINO MÉDIO \\ Karla Danielle da Silva Souza \\ Fernando Francelino Lopes Júnior}

A literatura brasileira tem importantes contribuições na elaboração do pensamento social brasileiro. Silvio Romero é um desses não especialistas que participam da formação desse pensamento social. A partir da centralidade que dava ao nacionalismo em suas obras literárias, Romero tratou de questões efervescentes em relação à ideia de "povo brasileiro". Para Dimas (2009), o crítico sergipano faz uma literatura atravessada pela história da construção da identidade nacional. Assim, sua obra História da literatura brasileira, publicada pela primeira vez em 1888, traz de um modo novo uma forma de caracterizar o país e, então, apresenta:

[...] um quadro orgânico e sistemático da literatura brasileira a um país que se esforçava para se deslocar de seu estatuto colonial. [...] Mais do que uma história da literatura, o crítico de Sergipe acabou por construir uma história da cultura brasileira, sob uma ótica racial carregada de demasias (p. 79).

Para além de Sílvio Romero, é importante destacar as relevantes contribuições de Euclides da Cunha e sua obra Os Sertões (1902), pela qual Romero é influenciado, e Gilberto Freyre com Casa-grande \& Senzala (1933). Posteriormente, surgem outros pensadores que colaboram para a elaboração teórica do pensamento social no Brasil. Destacamos três: Manoel Bonfim, Alberto Tôrres e Oliveira Viana. Esse primeiro pensador aponta a contribuição racial e cultura do índio e destaca a supervalorização da mestiçagem enquanto fenômeno positivo para a formação do povo brasileiro ressaltando sua função biológica e cultural no país.

Quanto a Alberto Tôrres, este afirmava que havia influência do meio sobre as raças, ou seja, elas se adaptavam conforme os diferentes espaços geográficos. Além disso, Tôrres se posicionava contra a teoria da superioridade de alguns povos sobre outros. Assim aponta Candido (2006):

As raças se ajustam diferentemente aos diferentes meios; o nosso é favorável aos povos mediterrâneos, devendo-se notar que os da Península lbérica são mesclados largamente de sangue africano; é 


\section{ENSINO DE CIÊNCIAS SOCIAIS NO BRASIL: A FORMAÇÃO DO \\ PENSAMENTO SOCIAL BRASILEIRO E AS LUTAS PELA INSTITUCIONALIZAÇÃO NO ENSINO MÉDIO \\ Karla Danielle da Silva Souza \\ Fernando Francelino Lopes Júnior}

também evidentemente favorável ao africano e ao nosso índio; neste caso, os nórdicos é que seriam aqui mesologicamente inferiores ( $p$. 280).

Apesar de considerar a existência de inferioridade das raças, se posicionava contra a mestiçagem por considerar que isso "enfraquece as qualidades das raças originais" (CANDIDO, 2006, p. 280). Diferentemente de Sílvio Romero e Manoel Bonfim, Tôrres criticava a mistura das raças, pois acreditava na organização da sociedade a partir da manutenção das raças em sua pureza biológica.

Já de Oliveira Vianna, destacamos sua preocupação teórica nas esferas política e administrativa. Compreendia o fator racial como relevante para explicar elementos da vida política brasileira, dessa forma, a capacidade de cada raça influenciava no funcionamento das instituições. Com isso, afirmava a existência dos critérios de superioridade e de inferioridade entre as raças.

Liedke Filho (2005) recorre a Azevedo ${ }^{1}$ ao afirmar que 0 desenvolvimento dos estudos de Sociologia e Antropologia sobre a sociedade brasileira precedem a etapa anterior à pesquisa - num período de meados do século XIX até 1928 - que se pautam na investigação das culturas indígenas. Ao passo que se desenvolviam essas pesquisas, avançavam também estudos que tinham o foco nos negros e na cultura africana no Brasil. De acordo com Filho (2005), esses dois eixos de pesquisa destacam-se como indicadores para o caminho para a institucionalização do ensino e da pesquisa e, portanto, do desenvolvimento da Sociologia no Brasil. Esse autor destaca três nomes essenciais que produziram pesquisas sobre a presença de negros e da

\footnotetext{
${ }^{1}$ Aprofundar em: AZEVEDO, Fernando. Princípios de Sociologia. São Paulo: Edições Melhoramentos, 1957.
} 


\section{ENSINO DE CIÊNCIAS SOCIAIS NO BRASIL: A FORMAÇÃO DO \\ PENSAMENTO SOCIAL BRASILEIRO E AS LUTAS PELA INSTITUCIONALIZAÇÃO NO ENSINO MÉDIO \\ Karla Danielle da Silva Souza \\ Fernando Francelino Lopes Júnior}

diversidade cultural africana no país, são eles: Batista Lacerda ${ }^{2}$, Nina Rodrigues ${ }^{3}$ e Roquette Pinto ${ }^{4}$.

Considerando que a formação do pensamento sociológico no Brasil parte dos primeiros estudos desenvolvidos por esses pensadores, vale ressaltar que esse período de institucionalização acaba sendo marcado por duas fases: a primeira corresponde ao final do século XIX relacionada à transição de uma sociedade que deixava de ser escravocrata. Destacam-se os estudos sociológicos como forma de interpretar o Brasil e analisar as relações sociais existentes, para isso aliava-se o Direito às teorias biológicas com a intenção de dar maior caráter científico a tais estudos (FILHO, 2005).

Segundo Filho (2005), a segunda fase se inicia no começo do século XX sob uma perspectiva mais pragmática com o objetivo de produzir estudos a partir de interpretações e intervenções racionais no processo de formação do pensamento sociológico. Surge uma Sociologia sob um modelo mais complexo para analisar a história do país, mas de uma forma mais prática, mais envolvida com o contexto e com as problemáticas sociais vigentes.

Todavia, é importante destacar a presença marcante do pensamento de Florestan Fernandes na institucionalização da Sociologia no Brasil. Esse autor apresenta outra perspectiva ao modo como se compreendia a Sociologia no país. De acordo com Octávio lanni (1996), Florestan inaugura uma nova época na história dessa jovem ciência, não só por mostrar novas possibilidades para a reflexão teórica e para a própria interpretação das relações sociais, mas também traz um olhar crítico sobre a então Sociologia brasileira. Assim, faz uma releitura crítica dos pensadores que o antecedem como Sílvio Romero,

\footnotetext{
${ }^{2}$ Batista Lacerda fazia parte do grupo de intelectuais que acreditava na solução do povo brasileiro por meio do branqueamento, afirmando, assim a superioridade da "raça" branca.

${ }^{3}$ A partir do estudo de campo em meio aos negros com o objetivo de melhor entender a sua cultura, Nina Rodrigues teve grande relevância para o início dos estudos sobre as questões raciais e impulsionar a reflexão dos pesquisadores brasileiros sobre o "problema do negro", do ponto de vista científico.

${ }^{4}$ Produziu pesquisas relacionadas aos temas de mestiçagem, desigualdade, branqueamento, imigração, entre outros. Trouxe uma perspectiva metodológica acerca das pesquisas sobre raças, especialmente como foco nos índios.
} 


\section{ENSINO DE CIÊNCIAS SOCIAIS NO BRASIL: A FORMAÇÂO DO \\ PENSAMENTO SOCIAL BRASILEIRO E AS LUTAS PELA INSTITUCIONALIZAÇÃO NO ENSINO MÉDIO \\ Karla Danielle da Silva Souza \\ Fernando Francelino Lopes Júnior}

Oliveira Vianna, Sérgio Buarque de Holanda, Gilberto Freyre, entre outros. E ainda retoma e desenvolve teses de outros autores como Euclides da Cunha, Manoel Bonfim, Caio Prado Júnior, e outros.

Para lanni (1996), Florestan traz uma nova forma de interpretar o Brasil a partir de elementos intrínsecos à formação da sociedade brasileira tais como: o desenvolvimento e as lutas do povo brasileiro. Ele chama atenção para a história do país fundamentada em relações desiguais que desencadearam os conflitos que atravessam a sociedade brasileira.

Florestan Fernandes se debruça, entre muitos temas, sobre as lutas que constituíam o cenário brasileiro: as revoltas das comunidades indígenas contra os colonizadores, as lutas contra o trabalho escravo, as lutas dos trabalhadores do campo e própria luta cotidiana para integração do negro na sociedade brasileira $^{5}$. Nesse contexto, procurou investigar como esses conflitos influenciam nas estruturas sociais e determinam as relações sociais.

Em relação à construção de uma teoria sociológica no Brasil, Florestan promoveu o diálogo com alguns autores fundadores da Sociologia, bem como os próprios clássicos: Spencer, Comte, Marx, Durkheim, Weber, entre outros. Além de fazer a crítica, Fernandes "formulou contribuições originais, abrindo novas possibilidades de reflexão" (IANNI, 1996, s/p).

Um dos temas mais presentes nas obras de Florestan Fernandes é a revolução social, ora como preocupação de ordem teórica, ora se configura como de ordem prática. Por isso, sua interpretação sobre a sociedade brasileira se concentra nas ideais acerca das transformações sociais. No entanto, vale ressaltar que seu pensamento não se limita a essas perspectivas, vão além. $O$ autor entra na discussão e reflexão sobre diversos temas como educação popular e a própria condição da profissão do cientista social. Isso nos mostra como Florestan era um intelectual de ampla visão sobre a Sociologia. Conseguia estabelecer diálogo com diversos autores, fazer a crítica

\footnotetext{
${ }^{5}$ Ver: FERNANDES, Florestan. A integração do negro na sociedade de classes. 3. ed. São Paulo: Ática, 1978 , v. 1.
} 


\section{ENSINO DE CIÊNCIAS SOCIAIS NO BRASIL: A FORMAÇÃO DO \\ PENSAMENTO SOCIAL BRASILEIRO E AS LUTAS PELA INSTITUCIONALIZAÇÃO NO ENSINO MÉDIO \\ Karla Danielle da Silva Souza \\ Fernando Francelino Lopes Júnior}

e avançar na discussão desses. Dono de uma obra extensa e múltipla, Fernandes: "Assinala o início de uma nova época na história da sociologia brasileira. Inaugura um novo estilo de pensamento sobre as configurações e os movimentos da sociedade. Permite conhecer o presente, repensar o passado e imaginar o futuro" (IANNI, 1996, s/p).

lanni (1996) afirma que Florestan Fernandes funda a Sociologia crítica no Brasil. Sua obra é marcada por um novo modelo de se fazer pesquisa científica no país por meio da reflexão que buscava questionar a realidade e 0 pensamento social. Sua perspectiva crítica atravessa toda sua produção intelectual, da militância às preocupações com as questões referentes ao ensino. Nesse sentido, esse autor vai além da explicação das teorias sobre a realidade social, estabelece uma nova Sociologia brasileira que supera o que está dado e estabelecido.

Outro fato que também marcou o processo de institucionalização da Sociologia no Brasil foi o período de ditadura militar. Etapa esta que traz modificações no cenário político, econômico e social do país no que diz respeito ao tipo de governo e às manifestações de pensamento. De acordo com Maria D'alva G. Kinzo (2001), o Brasil passou por uma experiência autoritária distinta dos demais países da América Latina se configurando a partir de algumas bases que estruturavam tal processo:

[...] uma tem a ver com as instituições políticas sob as quais o governo militar operava; e a outra, no domínio econômico, refere-se ao modelo de desenvolvimento seguido e suas consequências. No âmbito da política, há que se lembrar a emergência de uma situação bastante paradoxal. Por um lado, tratava-se de um regime tipicamente militar no sentido de que as Forças Armadas, enquanto instituição, passavam (após o golpe civil-militar que depôs João Goulart em 1964) a dirigir o país (s/p).

Os conflitos políticos vão ser desencadeados em consequência da disputa dentro da própria instituição militar o que gerava frequente instabilidade política no país. Todavia, eram mantidos os mecanismos referentes à 
ENSINO DE CIÊNCIAS SOCIAIS NO BRASIL: A FORMAÇÃO DO

PENSAMENTO SOCIAL BRASILEIRO E AS LUTAS PELA INSTITUCIONALIZAÇÃO NO ENSINO MÉDIO

Karla Danielle da Silva Souza

Fernando Francelino Lopes Júnior

democracia como o Congresso e o Judiciário, embora com poderes reduzidos e como muitos dos seus membros expulsos. Continuava a alternância na presidência da República; as eleições periódicas, funcionamento dos partidos políticos, embora esses procedimentos estivessem sob controle (KINZO, 2001).

O período de transição para a redemocratização no Brasil também se distingue dos demais países da América Latina. Teve maior durabilidade e foi marcado por três etapas, conforme aponta Kinzo (2001): a primeira delas (1974-1982) trata-se de um período inicial ainda sob domínio dos militares mais próxima de uma tentativa de reforma da ditadura do que uma transição; a segunda (1982-1985) se refere a um momento em que os civis passam a ter um papel mais importante, embora os militares ainda estivessem no poder; a terceira (1985-1989), por fim, é marcada pelo protagonismo pelos políticos civis e menor atuação dos militares, como também maior destaque e participação dos setores organizados da sociedade civil.

Nesse contexto de redemocratização abrem-se espaços para os diversos sujeitos sociais, para os direitos civis, sociais e políticos. A Sociologia também ganha maior abertura no cenário brasileiro - especialmente no ensino, como "um importante instrumento de cidadania" (FLORENCIO, 2009, p. 9).

\section{CONSIDERAÇÕES SOBRE A CULTURA BACHARELESCA NO BRASIL}

À história da Sociologia no Brasil estão ligados aspectos de formação cultural de ordem colonizadora que tem se prolongado até os dias atuais. Elementos de status e distinção social atravessam a sociedade brasileira desde sua transição de colônia à pós-colonização.

A partir de Manoel Bomfim, Menezes (2009) afirma que o bacharelismo não é um fenômeno exclusivo do Brasil e que resulta das relações entre os grupos sociais que se formaram nas sociedades pós-coloniais latinoamericanas. Assim, a tradição bacharelesca tem na atividade intelectual uma 


\section{ENSINO DE CIÊNCIAS SOCIAIS NO BRASIL: A FORMAÇÂO DO \\ PENSAMENTO SOCIAL BRASILEIRO E AS LUTAS PELA INSTITUCIONALIZAÇÃO NO ENSINO MÉDIO \\ Karla Danielle da Silva Souza \\ Fernando Francelino Lopes Júnior}

força de distinção, encontrando espaço nas atividades relacionadas às profissões de médicos, juristas e engenheiros, principalmente.

Historicamente, o povo português mantinha uma cultura de diferenciação social e supervalorização do poder. Assim, segundo Menezes (2009), a necessidade que o português tinha de mostra-se importante desencadeava comportamentos sociais elitizados, o que acabou influenciando no processo de colonização do Brasil de forma mais aristocrática do que nos demais países latino-americanos. Nesse sentido, tentou-se reafirmar e solidificar essa distinção por meio de diversas maneiras:

[..] a saudade de um passado de esplendor levou o colonizador português a uma exagerada necessidade de distinção social, a qual transparece na enorme vastidão de terras, de escravos, de roupas quentes de seda, de porcelanas e da prataria ostentados pelos portugueses (MENEZES, 2009, p. 97).

Todavia, Menezes, a partir de Holanda (1995), ainda ressalta que, ao português, não foi suficiente a prática de ostentação de riquezas materiais como forma de tentar legitimar sua suposta superioridade, visto que o Brasil passou por fortes processos de instabilidade da riqueza rural. Como sentia extrema necessidade de manter determinada distância social dos demais sujeitos que habitavam o Brasil, o colonizador buscou estratégias para dar continuidade a esse imaginário.

A partir do século XIX, a sociedade escravocrata começa a se desfazer e a lógica aristocrática, com sua produção de riquezas, vai sendo substituída por outros modelos de sociedade. No caso, estava a surgir um Estado moderno, burocrático e impessoal. É nesse contexto que o bacharelismo se difunde entre as famílias da elite do país. Estas podiam proporcionar os estudos dos filhos fora do país, buscando reforçar lugares de distinção a partir da educação. O fenômeno do bacharelismo vem substituir a diferença social que se fundamentava na propriedade rural diante de uma mudança significativa de modelo de sociedade. 


\section{ENSINO DE CIÊNCIAS SOCIAIS NO BRASIL: A FORMAÇÃO DO \\ PENSAMENTO SOCIAL BRASILEIRO E AS LUTAS PELA INSTITUCIONALIZAÇÃO NO ENSINO MÉDIO \\ Karla Danielle da Silva Souza \\ Fernando Francelino Lopes Júnior}

Freyre, em seu livro Sobrados e Mucambos (2004), mostra como o surgimento dos bacharéis está ligado à transição do cenário rural para 0 moderno em um processo de urbanização que afeta o tipo de sociedade em vigor. $O$ autor chama a atenção para a centralidade de duas figuras nesse contexto: o bacharel e o mulato. Esses dois elementos seriam os principais fatores de diferenciação social em uma sociedade em transformação.

Freyre (2004) afirma que havia também a distinção entre os próprios bacharéis. Àqueles pobres e os considerados "de cor" eram dificultados os caminhos de ascensão social. Como, em geral, não dispunham de protetores políticos, muitas vezes ascendiam socialmente por meio do casamento "com moça rica ou de família poderosa" (p.722).

Segundo Menezes (2009), outro fenômeno veio corroborar nesse processo de formação de uma elite intelectual que procurava estabelecer distância do povo, era a "burguesia letrada" que se apresentava como capaz de ocupar cargos na monarquia (p. 98, grifo da autora). Ademais, havia outra característica comportamental que tem deixado resquícios na mentalidade do povo brasileiro: a classe intelectual brasileira, com fortes heranças portuguesas, afirma horror ao trabalho manual.

Assim, a autora nos diz que, entre os principais aspectos de ordem colonial que foram herdados e transpostos à formação dos intelectuais brasileiros foram: "a aristocratização, o legalismo, o colaboracionismo político, o messianismo e o distanciamento das atividades manuais" (MENEZES, 2009, p. 99). Esses elementos colaboram para a constituição do pensamento da elite e interiorização dessas concepções pelo povo. Além das contribuições dos intelectuais à monarquia, traço peculiar no Brasil, outros fatores também decorreram a partir da necessidade dessa elite, especialmente, na colaboração para construção da identidade de uma nação em surgimento. Era necessário pensar e escrever a história do país e para isso contava-se com os filhos da elite que tiveram acesso à educação formal e superior. 


\title{
ENSINO DE CIÊNCIAS SOCIAIS NO BRASIL: A FORMAÇÂO DO \\ PENSAMENTO SOCIAL BRASILEIRO E AS LUTAS PELA INSTITUCIONALIZAÇÃO NO ENSINO MÉDIO \\ Karla Danielle da Silva Souza \\ Fernando Francelino Lopes Júnior
}

Assim como Menezes, recorremos também a Sérgio Buarque de Holanda (1995) para ressaltar a importância que se dava ao bacharel no referido contexto:

\begin{abstract}
A dignidade e importância que confere o título de doutor permitem ao indivíduo atravessar a existência com discreta compostura e, em alguns casos, podem libertá-lo da necessidade de uma caça incessante aos bens materiais, que subjuga e humilha a personalidade (p. 157).
\end{abstract}

Ainda conforme Menezes (2009), os bacharéis tinham o papel de agentes de transformação social. Usavam teorias importadas com o objetivo de modernizar o país a partir da elite, desconsiderando a participação direta do povo. Dessa forma, podemos perceber o interesse e a insistência que a elite tinha em reafirmar constantemente a distinção social: "[...] quando um indivíduo era de origem popular, como no caso dos intelectuais mulatos, estes só atingiam o reconhecimento social de agente político ao se formarem e com isto se "europeizarem" em seus modos de pensar e viver" (p. 105).

Por tudo isso, nota-se que o bacharelismo marca a mudança de uma sociedade aristocrática para a emergência do Estado moderno. Com isso, provocando transformações no modo de vida, antes tradicional para 0 moderno. Daí se explicava o interesse dos bacharéis pelo novo e pelos modismos estrangeiros, conforme aponta Menezes (2009).

\section{ENSINO DE CIÊNCIAS SOCIAIS NO BRASIL}

Liedke Filho (2005) aponta o início da Sociologia de cátedra nos países latino-americanos por volta do fim do último século, sendo introduzidas as referidas cátedras a partir das Faculdades de Filosofia, Direito e Economia. No Brasil, isso ocorre na década de vinte com a criação das cadeiras de Sociologia nas Escolas Normais (1924-1925) de modo secundário auxiliando a pedagogia. O movimento escolanovista se configura como espaço de maior expressão 


\section{ENSINO DE CIÊNCIAS SOCIAIS NO BRASIL: A FORMAÇÂO DO \\ PENSAMENTO SOCIAL BRASILEIRO E AS LUTAS PELA INSTITUCIONALIZAÇÃO NO ENSINO MÉDIO \\ Karla Danielle da Silva Souza \\ Fernando Francelino Lopes Júnior}

para a sociologia naquele momento. Inspiradas na sociologia dos europeus e dos norte-americanos, as publicações no Brasil se intensificaram com temáticas relacionadas a problemas sociais diversos, como: urbanização, migrações, analfabetismo e pobreza. Além da perspectiva vigente sobre a miscigenação como um aspecto positivo. Por esse viés é que, segundo o autor, não se deve atribuir a origem do ensino de sociologia no país a um único fator. Há uma multiplicidade de elementos que se relacionam decorrentes dos contatos e conflitos entre povos e culturas diversas.

À institucionalização e prática do ensino e da pesquisa em Sociologia no Brasil está relacionada à emergência da Sociologia científica, processo semelhante aos dos centros sociológicos dos países centrais. Assim, o ensino de Sociologia no país se configura em um cenário que também se busca a institucionalização enquanto ciência, desse modo, ambos os processos (ensino e pesquisa), muitas vezes, caminham juntos e se entrelaçam com frequência.

Um ponto destacado por Filho (2005) que, segundo o autor, tem grande relevância é que a institucionalização da Sociologia e da Ciência Política no ensino superior no Brasil - na Escola Livre de Sociologia e Política de São Paulo - se efetiva a partir dos interesses da elite paulista. Seu objetivo, segundo Filho recorre a Oliveira ${ }^{6}$, era atender à falta de uma elite intelectual em maior número e mais organizada com a finalidade de compreender $\mathrm{o}$ contexto em que estavam inseridos.

A História da Sociologia passa por constantes avanços e retrocessos. Seu caráter de intermitência é acompanhado e influenciado pelos momentos políticos, econômicos e sociais pelos quais o Brasil passou. Os conflitos ideológicos intrínsecos à formação do sistema de educação brasileira incidem diretamente na instituição da Sociologia no ensino do país. Nesse contexto, é possível apontar cinco momentos centrais de todo esse processo de inconstância da sua obrigatoriedade, segundo Filho (2005). O primeiro deles é

\footnotetext{
${ }^{6}$ OLIVEIRA, J. A. M. de, et alii Manifesto de Fundação da Escola Livre de Sociologia e Política de São Paulo (1933). In: FÁVERO, M. de L. de A Universidade \& Poder. Rio de Janeiro: Achiamé, 1980.
}

Inter-Legere - Revista de Pós-Graduação em Ciências Sociais da UFRN 


\section{ENSINO DE CIÊNCIAS SOCIAIS NO BRASIL: A FORMAÇÂO DO \\ PENSAMENTO SOCIAL BRASILEIRO E AS LUTAS PELA INSTITUCIONALIZAÇÃO NO ENSINO MÉDIO \\ Karla Danielle da Silva Souza \\ Fernando Francelino Lopes Júnior}

marcado pela iniciativa de Rui Barbosa quando, em 1882, apresentou um projeto que visava a reestruturação do ensino, nele aparecendo a primeira proposta de inclusão da Sociologia no curso secundário. No entanto, somente após a Proclamação da República, com a reforma implantada por Benjamin Constant, é que a Sociologia é introduzida no Brasil. Com a morte de Constant, a disciplina não é integralmente implementada. Assim, com a Reforma Epitácio Pessoa, a Sociologia sai do currículo em 1901 antes mesmo de ser ofertada.

O segundo momento é marcado por algumas reformas. Em 1925, a Reforma do ministro Rocha Vaz estabelece o ensino de Sociologia na $6^{\underline{a}}$ serie do curso ginasial e seus conhecimentos aliados às elites de bacharéis. A Reforma de Francisco Campos, de 1931, ainda com o caráter de preparatória para o ensino superior. Desse modo, sua "obrigatoriedade" se limita a uma complementaridade. E ainda, com a Reforma de Gustavo Capanema, em 1942, por meio do regime autoritário de Getúlio Vargas a disciplina é excluída novamente.

A terceira etapa é constituída no período de redemocratização do país. Embora alguns intelectuais tenham lutado pela reinclusão da disciplina, até mesmo a primeira Lei de Diretrizes e Bases, de 1961, não possibilita avanços. Essa lei deixa espaço para autonomia dos estados para inclusão da Sociologia. Mesmo com as reformas seguintes ela não é contemplada.

Com o processo de redemocratização do país, mais uma vez, a disciplina tem determinada retomada ao ensino. Esse quarto momento é marcado por mais mudanças e reformas na educação. $O$ ensino passa a ter dois formatos: um acadêmico e outro profissionalizante. O período também foi marcado por mobilizações, lutas e manifestações por parte de Sociólogos, políticos, educadores e estudantes em prol da obrigatoriedade do ensino da disciplina. A instalação da Assembleia Nacional Constituinte (1986) e a criação de alguns órgãos relacionados à Sociologia contribuem para a luta por um campo legitimado. O vestibular de 1994 foi decisivo para pensar a 
ENSINO DE CIÊNCIAS SOCIAIS NO BRASIL: A FORMAÇÃO DO

PENSAMENTO SOCIAL BRASILEIRO E AS LUTAS PELA INSTITUCIONALIZAÇÃO NO ENSINO MÉDIO

Karla Danielle da Silva Souza

Fernando Francelino Lopes Júnior

obrigatoriedade da Sociologia como disciplina, pois o mesmo requeria do aluno uma formação ética, social e reflexiva.

\section{ENSINO DE SOCIOLOGIA NA EDUCAÇÃO BÁSICA}

A Lei no 11.684/08 altera a de ํo 9.394 de 1996 e estabelece as diretrizes e bases da educação nacional, para incluir a Filosofia e a Sociologia como disciplinas obrigatórias nos currículos do ensino médio. Como mencionado anteriormente nesse texto, os períodos de intermitência da Sociologia na educação influenciam diretamente na forma como se compreendeu/compreende o papel dela no Ensino Médio.

$O$ atual contexto exige atenção, pois vivemos em período de exceção no qual direitos estão sendo suprimidos, avanços e conquistas estão sendo derrubados diante do processo de Impeachment sobre a presidenta Dilma Roussef ocorrido em agosto do ano de 2016. A partir da imposição de uma Medida Provisória que desconsidera todo o debate para construção da Base Nacional Comum Curricular, a educação brasileira sofre graves consequências. Dentro desse contexto, algumas disciplinas estão ameaçadas de exclusão dos currículos escolares na Educação Básica, entre elas, mais uma vez, Sociologia.

Não por acaso tais disciplinas correm o risco de serem extintas novamente, conforme já mencionamos no primeiro capítulo desse texto. Ambas promovem ao estudante uma capacidade de autonomia, de crítica, de análise sobre o mundo a sua volta e sua realidade local, para além da formação do cidadão como aponta os documentos oficiais (OCN's e PCN's, 2006).

Diante desse não tão novo cenário, percebemos que a exclusão dessas disciplinas segue uma lógica atrelada a um projeto de Estado que pretende formar com foco para o mercado de trabalho. Dessa forma, em se tratando de um governo ilegítimo, compreendemos que tais disciplinas perdem espaço e oferecem risco à ideologia dominante, pois, conforme discutimos, possibilitam 


\section{ENSINO DE CIÊNCIAS SOCIAIS NO BRASIL: A FORMAÇÃO DO \\ PENSAMENTO SOCIAL BRASILEIRO E AS LUTAS PELA INSTITUCIONALIZAÇÃO NO ENSINO MÉDIO \\ Karla Danielle da Silva Souza \\ Fernando Francelino Lopes Júnior}

maior capacidade crítica e reflexiva em relação ao lugar que ocupa socialmente e tudo a sua volta.

\section{CONSIDERAÇÕES FINAIS}

Dada a intermitência do ensino de Sociologia na Educação Básica, o que acontece a mais de um século, além de ocorrer de forma a interpretar as relações locais segundo teorias estrangeiras, tendo diversos autores que abrangem as mais diversas perspectivas do pensamento sociológico que vão desde as teorias biodeterministas, passando pela identidade miscigenada e imaginário brasileiro, os conteúdos devem ser alinhados pelos educadores de modo a estipular uma sociologia brasileira a ser apresentada nas escolas.

Para tanto é necessário, inclusive, reforçar o desenvolvimento de teóricos brasileiros no Ensino Superior para que estes possam elaborar com maior segurança conteúdos que contemplem tais abordagens, uma vez que os Parâmetros Curriculares não têm indicações concretas sobre como e quais títulos abordar no ensino.

Nesse sentido, o trabalho educativo no Ensino Médio precisa começar pela firmação da necessidade de uma proposta de ensino que parta dos fóruns compostos pelos educadores para, então, definirmos a unidade nos assuntos que precisamos abordar. Só assim deixaremos de escrever sobre a intermitência do ensino de sociologia e passaremos a colher os frutos de um conteúdo teórico que verse sobre nossa realidade social e, com isso, possibilitar, inclusive, uma sociedade entendida de sua história e autônoma em suas projeções.

Em síntese, para uma disciplina que tem como proposta ir além de formar o indivíduo "cidadão", é necessário fundar-se com base na preocupação de propor a crítica como prática de ensino, promovendo o estranhamento e a 
ENSINO DE CIÊNCIAS SOCIAIS NO BRASIL: A FORMAÇÃO DO

PENSAMENTO SOCIAL BRASILEIRO E AS LUTAS PELA INSTITUCIONALIZAÇÃO NO ENSINO MÉDIO

Karla Danielle da Silva Souza

Fernando Francelino Lopes Júnior

desnaturalização como conceitos norteadores e ainda de forma tematizada como sugerem as orientações curriculares.

Dada a construção do imaginário social brasileiro que, em meio a diversas outras produções, também pouco considera sua produção intelectual e pouco explora a Sociologia que se produz localmente. Embora com grandes contribuições teóricas para formação do pensamento social brasileiro, é preciso perceber que a Sociologia não deve se limitar à transposição de teorias, mas fazer o que propôs Florestan Fernandes: uma Sociologia crítica e pragmática que pense a realidade local e atual diante de suas problemáticas que estão, principalmente, no seio da sociedade brasileira, conforme sinaliza lanni (1996).

\section{REFERÊNCIAS}

AZEVEDO, Fernando. Princípios de Sociologia. São Paulo: Edições Melhoramentos, 1957.

BRASIL. MEC. SEF. Orientações Curriculares para o Ensino Médio: Ciências Humanas e suas Tecnologias. Brasília: MEC/SEF, 2006. . MEC. SEF. Orientações Educacionais Complementares aos Parâmetros Curriculares Nacionais: Ciências Humanas e suas Tecnologias. Brasília: MEC/SEF, 2006.

CANDIDO, Antonio. A Sociologia no Brasil. Tempo Social, revista de sociologia da USP, v. 18, n. 1 junho 2006. Disponível em:

http://www.scielo.br/pdf/ts/v18n1/30018.pdf

DIMAS, Antonio. O turbulento e fecundo Sílvio Romero. In: BOTELHO, A.; SCHWARCZ, L. (Orgs.) Um enigma chamado Brasil. São Paulo: Companhia da Letras, 2009.

LIEDKE FILHO, Enno D. A Sociologia no Brasil: história, teorias e desafios. Sociologias, Porto Alegre, Ano 7, № 14, Jul/Dez 2005, p. 376 - 437. <http://www.scielo.br/pdf/soc/n14/a14n14.pdf> Acesso em: 17 mai. 2015.

FLORENCIO, M. A. L. A sociologia no ensino médio: O percurso histórico no Brasil e em Alagoas. TRABALHO APRESENTADO NA SBS 2009. 


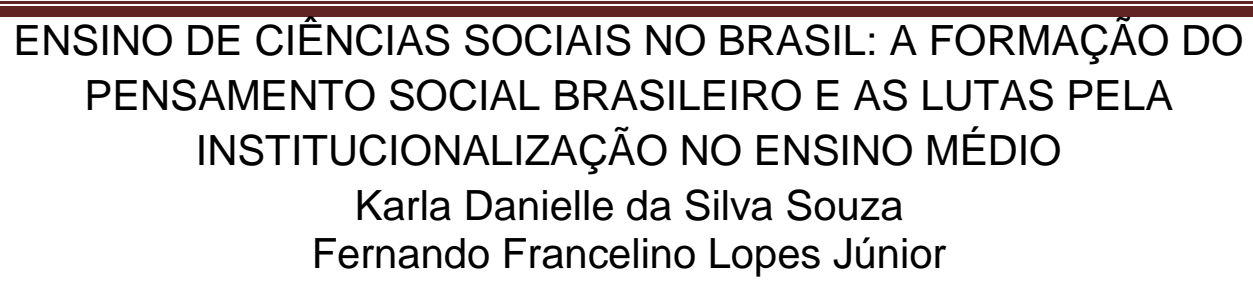

FREYRE, Gilberto. Sobrados e Mocambos: decadência do patriarcado e desenvolvimento do urbano. - 15aㅡ ed. São Paulo: Global, 2004.

HOLANDA, Sérgio Buarque. Raízes do Brasil. 26. ed. São Paulo: Companhia das Letras, 1995.

IANNI, Octavio. A Sociologia de Florestan Fernandes. Estud. av. vol.10 no.26 São Paulo Jan./Apr. 1996. Disponível em: http://www.scielo.br/scielo.php?script=sci_arttext\&pid=S010340141996000100006

KINZO, Maria D'Alva Gil. Partidos, eleições e democracia no Brasil pós-1985. In: Rev. Bras. Ci. Soc., fev 2004, v.19, n.54, p.23-40. Disponível em: <http://www.scielo.br/pdf/rbcsoc/v19n54/a02v1954.pdf>. Acesso em: 11 jun. 2016.

MENEZES, Anna Waleska N. C. de. O fenômeno do bacharelismo à luz de Gilberto Freyre. Inter-legere (UFRN), v. 5, p. 95-107, 2009. 